\title{
BULlWHIP EFFECT Simulation OF A SUPPLY Chain With LeVel Constraints
}

\author{
BUCHMEISTER, B. \& PALCIC, I.
}

Abstract: For make-to-stock production systems the production plans and activities are based mainly on demand forecasting, which is one of the key causes of the bullwhip effect. The bullwhip effect $(B E)$ is the inherent increase in demand fluctuation up the supply chain. In the paper we have illustrated the phenomenon of bullwhip effect using real demand data in three simulation cases of a supply chain with different level constraints. We experimented with a simple three-stage supply chain using seasonal and deseasonalized time series of the market demand data in order to identify, illustrate and discuss the impacts of different level constraints on the BE. The results are presented for different overall equipment effectiveness (OEE) and constrained inventory policies. At higher OEE level there is less variability in production processes, but at inventory limitations the impact is more complex. The goals of this paper are to discuss the causes of the BE and investigate the potential benefit that information sharing offers for overcoming these problems.

Key words: supply chain, simulation, bullwhip effect, capacity constraints, real data
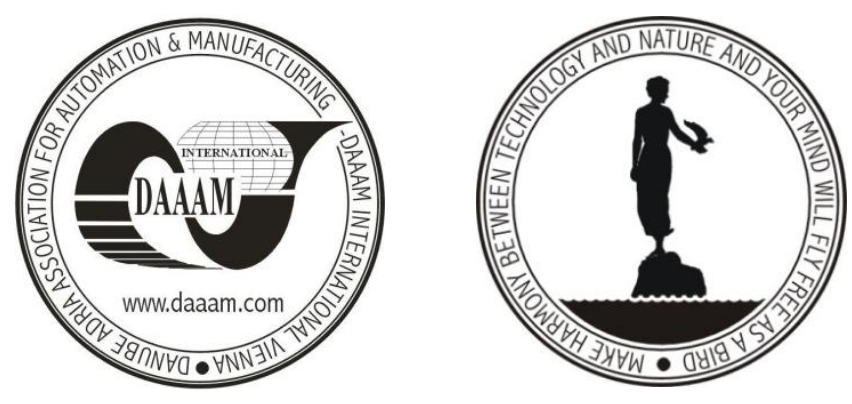

Authors' data: Assoc. Prof. Dr. Sc. Buchmeister, B[orut]; Assist. Prof. Dr. Sc. Palcic, I[ztok], University of Maribor, Faculty of Mechanical Engineering, Laboratory for Production Management, Smetanova 17, SI - 2000, Maribor, Slovenia, EU, borut.buchmeister@um.si, iztok.palcic@um.si

This Publication has to be referred as: Buchmeister, B[orut] \& Palcic, I[ztok] (2013) Bullwhip Effect Simulation of a Supply Chain with Level Constraints, Chapter 05 in DAAAM International Scientific Book 2013, pp. 133-148, B. Katalinic \& Z. Tekic (Eds.), Published by DAAAM International, ISBN 978-3-901509-94-0, ISSN 1726-9687, Vienna, Austria

DOI: $10.2507 /$ daaam.scibook.2013.05 


\section{Introduction}

Supply chain management (SCM) is one of the most important and developing areas. It includes basically demand fulfilment, demand planning and supply planning. It integrates internal and external logistics across many manufacturers, suppliers, distributors, retailers, and transportation providers to increase productivity and to obtain a competitive advantage for all parties involved (Fig. 1). The objective of supply chain management is to provide a high velocity flow of high quality, relevant information that will enable suppliers to provide an uninterrupted and precisely timed flow of materials to customers. The idea is to apply a total systems approach to managing the entire flow of information, materials, and services from raw materials suppliers through factories and warehouses to the end customer.

The original motive of SCM was "elimination of barriers between trading partners" in order to facilitate synchronization of information between them (Gilbert \& Ballou, 1999). But in real business this idea became lost. Where is the main problem? Supply chain performance depends on the operation of all members in a supply chain, where each member's basic objective is the optimisation of its own performance. Such behaviour of members can lead to less optimal whole chain performance. Members of a supply chain are used to compete and not to co-operate; they don't share information about products, customers, inventories, production capacities, costs and other business processes. So the members don't know much about the real market situation and the efficiency in their chain. They just repeat five basic activities in their supply chain: buy, make, move, store and sell.

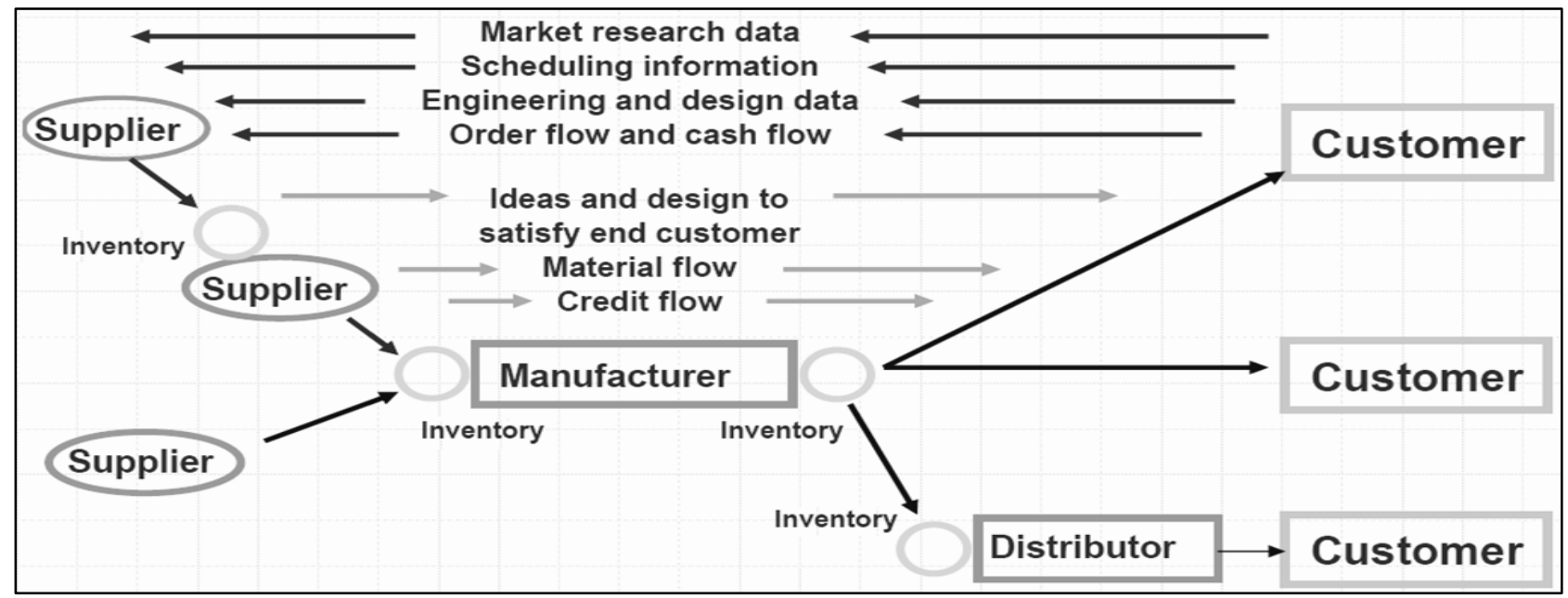

Fig. 1. Flows in a supply chain (information, material, money)

Simulation is a very powerful and widely used management science technique (Ben Said et al., 2010) for the analysis and study of supply chains. The most important types are: spreadsheet simulation, system dynamics, discrete-event simulation, and business games.

The bullwhip effect represents the phenomenon of demand distortion where orders to supplier tend to have larger variance than sales to the buyer and this distortion propagates upstream in an amplified form. 
Many companies are faced with the bullwhip effect and its consequences, but to understand the causes it is helpful to study it in a controlled environment. Eliminating the bullwhip effect can then increase product profitability by approximately $15-20 \%$.

In the paper we are giving a brief literature review of newer publications dealing with the bullwhip effect (section 2), continued with the presentation of the data used in the model (section 3) and our analysis of the influence of level constraints in the modelled supply chain (sections 4 and 5). Finally, section 6 contains a conclusion of the work and the future work.

\section{Literature Review}

Numerous studies focused on identifying the bullwhip effect in examples from individual products and companies. In our previous publications (Buchmeister et al., 2008; Buchmeister, 2008) the literature review about related work regarding bullwhip effect from its first observations including causes and consequences has been presented (Forrester, 1961; Sterman, 1989; Lee et al., 1997; Simchi-Levi et al., 2003). Within supply chain environment, end users form the demand for the last company in the supply chain, but the demand for upstream companies is formed by the companies in the immediate downstream supply chain link. It has been shown that demand seasonality and forecast error can increase as we proceed up the supply chain. These demand distortions, called the bullwhip effect, create inefficiencies for upstream firms (Metters, 1997). This work seeks to identify the magnitude of the problem by establishing an empirical lower bound on the profitability impact of the bullwhip effect.

A number of researchers designed games to illustrate the Bullwhip Effect. The most famous game is the "Beer Distribution Game" (***, 1963). It was developed at MIT to simulate the Bullwhip Effect in an experiment, and has been used widely for five decades. Some newer selected publications from the last eight years are summarised below.

Within general supply chain topics Carvalho and Machado (2009) presented a review of actual (lean, agile, resilient, green) SCM paradigms, identifying the attributes of each paradigm and their impact/consequence in the supply chain. They presented a conceptual model to provide the necessary understanding of synergies and divergences of paradigms and investigated the possibility to merge them, in order to contribute for a more sustainable and competitive supply chain. Pochampally et al. (2009) addressed the metrics that help evaluate the performance of reverse and closed-loop supply chains. These metrics are incorporated in a mathematical model that uses quality function deployment (QFD) and linear physical programming (LPP) effectively to measure the 'satisfaction level' of the supply chain. Lyons et al. (2012) introduced the subject of supply chain performance measurement and proposed a series of inter-organisational metrics that are compatible with the notion of customerdriven supply chain design. Despite there being many different approaches to measure supply chain performance, there is no one perfect measurement approach that can suit all supply chains. 
Pishvaee et al. (2011) proposed a robust optimization model for handling the inherent uncertainty of input data in a closed-loop supply chain network design problem, which is the one of the primary works in this field. The related semi-definite model is formulated according to studied uncertain parameters. Computational results show the superiority of the proposed model in both handling the uncertain data and the robustness of respective solutions against to the solutions obtained by the deterministic model.

Benyoucef and Xie (2011) presented a simulation-based multi-objective optimisation approach for design of supply chain networks by integrating the strategic network configuration decisions and the selection of best-suited operation strategies. They addressed the related operational decisions such as order splitting, transportation allocation and inventory control. The goal was to achieve the best compromise between cost and customer service level.

Alony and Munoz (2007) reviewed the various methods of modelling the dynamics of supply chains. They examined the limitations of modelling methodologies (analytical, agent-based, simulation) and suggested a combined discrete event and continuous simulation modelling approach. Pujawan (2008) investigated how different supply chain policies and different operating environments affect schedule instability in a supply chain. It is shown that schedule instability is propagated up the supply chain and is much affected by the degree of demand uncertainty from the end customers, and that safety stock policy applied by the buyer has much impact on schedule instability.

Disney (2009) reviewed a range of methodological approaches to solving the bullwhip problem. Measures for the bullwhip are given. Different types of supply chains (traditional - Fig. 2, information sharing, vendor managed inventory) are described and as a whole it is a general overview including also replenishment policies, forecasting techniques, lead times, costs etc.

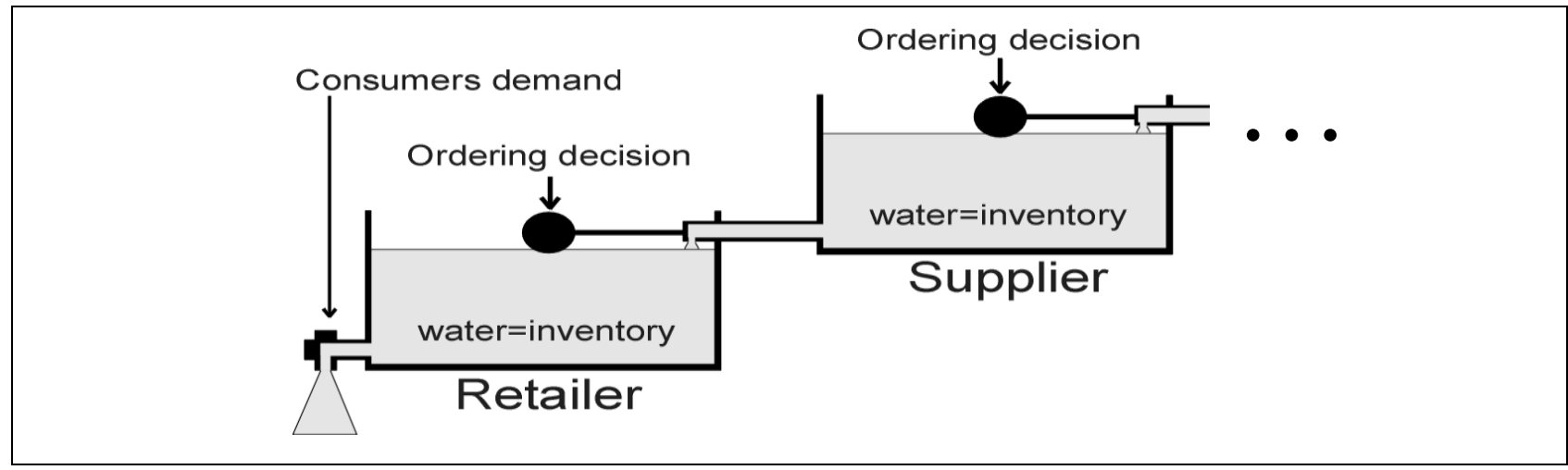

Fig. 2. Schematic of a traditional supply chain (Gilbert \& Ballou, 1999)

Ouyang and Li (2010) analysed the propagation and amplification of order fluctuations in supply chain networks (with multiple customers) operated with linear and time-invariant inventory management policies. The paper gives analytical conditions to predict the presence of the bullwhip effect to any network structure and any inventory replenishment policy, using a system control framework for analysing 
order stability. It provides the basis for modelling complex interactions among suppliers and among customer demands.

Glatzel et al. (2009) described the bullwhip effect problem on many practical cases from global manufacturing industry aspect with the emphasis to find new ways of thinking and decision making to assure enough flexibility in business. Cachon et al. (2007) made observations and evaluated the strength of the bullwhip effect in U.S. industry using official data from period 1992-2006. They did not observe the bullwhip effect among retailers and among manufacturers, but the majority of wholesalers amplified. They explained also that highly seasonal industries tend to smooth demand volatility whereas nonseasonal industries tend to amplify.

Chen and Lee (2012) developed a set of formulas that describe the traditional bullwhip measure as a combined outcome of several important drivers (finite capacity, batch ordering, seasonality). They discussed the managerial implications of the bullwhip measurement and showed that an aggregated measurement over relatively long time periods can mask the operational-level bullwhip. Duc et al. (2008) quantified the bullwhip effect, the variance amplification in replenishment orders, for cases of stochastic demand and stochastic lead time in a two-stage supply chain. They investigated the behaviour of a measure for the bullwhip effect with respect to autoregressive coefficient and stochastic order lead time. Sucky (2009) focused in his work on measuring the bullwhip effect taking into consideration the network structure of supply chains. He shows that the bullwhip effect is overestimated if just a simple (two stage) supply chain is assumed and risk pooling effects are present. The strength of the effect depends on the statistical correlation of the demands. Ouyang and Daganzo (2006) presented a system control framework for analyzing the bullwhip effect in decentralized, multiechelon supply chains operated with linear, time-invariant policies. They derived robust analytical conditions to predict whether or not the bullwhip effect will arise without knowing the customer demand, and they also developed exact formulae for the variance of the order stream at any level of a multi-stage chain knowing only the spectrum of the customer demand process and the set of policies. In their second paper (Ouyang and Daganzo, 2008) they presented a control framework to analyse the bullwhip effect in singlestage supply chain under exogenous Markovian uncertainty. They derived robust analytical conditions that diagnose the bullwhip effect and bound its magnitude. The results are useful for prediction of performance in uncertain operating environments.

Shaikh and Khan (2008) quantified twenty factors responsible for the bullwhip effect. Their study is based on Middle East situation; the data were collected using a survey form. The most critical factors observed are Substitution products (Competition) and Seasonal effect.

Agrawal et al. (2009) analysed a two stage serial supply chain. They studied the impact of information sharing and lead time on bullwhip effect and on-hand inventory. It is shown that some part of bullwhip effect always remain after sharing both inter- and intra-stage data and that the lead time reduction is far more beneficial.

Bray and Mendelson (2012) analysed the bullwhip by information transmission lead time based on public companies' data from years 1974-2008. Shorter reaction times cause significantly more troubles regarding bullwhip.

Oyatoye in Fabson (2011) explored the simulation approach in quantifying the effect of bullwhip in supply chain, using various forecasting methods. They 
emphasized a problem of inadequate information in a supply chain. Kelepouris et al. (2008) studied how specific replenishment parameters affect order variability amplification, product fill rates and inventory levels across the chain. Short lead times are essential for the efficient operation of the supply chain. They investigated also how demand information sharing can help towards reducing order oscillations and inventory levels in upper nodes of a supply chain. The model represents a simple two-stage supply chain with real demand data. Tominaga et al. (2008) investigated the influence of safety parameters for inventory control policy (safety stocks) on bullwhip effect and its relationship to costs and total profit, with present demand uncertainty in the modelled supply chain. Csik and Foldesi (2012) tested the problem of bullwhip effect by adoption of an inventory replenishment policy involving a variable target level, where all other common causes were excluded. Safety stock was proportional to the actual demand. They proposed a new production plan, which guarantees the stability of the entire supply chain. Croson and Donohue (2006) studied the bullwhip phenomenon from a behavioural perspective. They found that bullwhip effect still exists when normal operational causes (e.g., batching, price fluctuations, demand estimation, etc.) are removed. They observed that inventory information helps somewhat to alleviate the bullwhip effect by helping upstream chain members better anticipate and prepare for fluctuations in inventory needs downstream.

Nepal et al. (2012) presented an analysis of the bullwhip effect and net-stock amplification in a three-stage supply chain considering step-changes in the production rates during a product's life-cycle demand. The simulation results show that performance of a system as a whole deteriorates when there is a step-change in the life-cycle demand.

Akkermans and Voss (2010) checked the bullwhip effect in services. They investigated how this effect manifests itself in services (differently: build-ups of work backlogs, peaks of workloads, customer calls and complaints), which are the drivers (behaviour) and which actions trigger (lack of visibility) or mitigate (reduction of work backlog) the bullwhip effect.

\section{Data and Model Presentation}

Our study is dealing with single product / multi-level supply chain using real market demand data with present variability (demand with moderate linear trend, we calculate with seasonality and deseasonalized). Information (orders) in the chain flow on a weekly basis. We have collected a time series of the market demand data with seasonal characteristics for 48 weeks (= periods; in their order of occurrence all are given in Table 1), shown also in Fig. 3 where we added the deseasonalized values for the time series.

\begin{tabular}{|l|c|c|c|c|c|c|c|c|c|c|c|c|}
\hline Weeks 1-12 & 48 & 65 & 85 & 117 & 134 & 143 & 145 & 122 & 90 & 83 & 55 & 51 \\
\hline Weeks 13-24 & 54 & 61 & 97 & 145 & 138 & 144 & 135 & 121 & 89 & 81 & 52 & 26 \\
\hline Weeks 25-36 & 44 & 61 & 87 & 131 & 139 & 157 & 155 & 154 & 106 & 89 & 44 & 38 \\
\hline Weeks 37-48 & 54 & 76 & 119 & 154 & 172 & 179 & 166 & 152 & 121 & 97 & 51 & 48 \\
\hline
\end{tabular}

Tab. 1. Market demand variation for the single product (original values) 
Statistical analysis shows that we have 48 data, minimal demand is 26 , and maximal demand is 179 . Average demand is 102; mode 97, standard deviation is 43 (for original demand) and 11 (for deseasonalized demand).

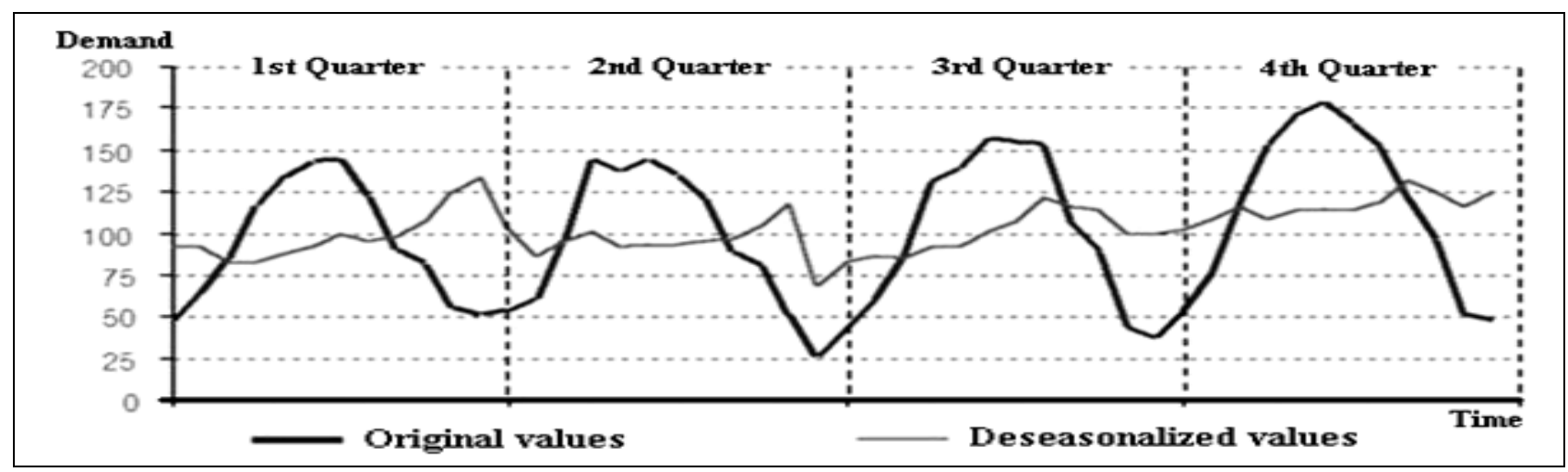

Fig. 3. Market demand of the product (original and deseasonalized values)

Deseasonalization is performed using the chain indexing method. In all models (SM - seasonal model and DSM - deseasonalized model) the 48 periods with continuous reviewing were simulated. The simulation model comprises a three-stage supply chain consisting from single retailer, manufacturer and supplier (Fig. 4).

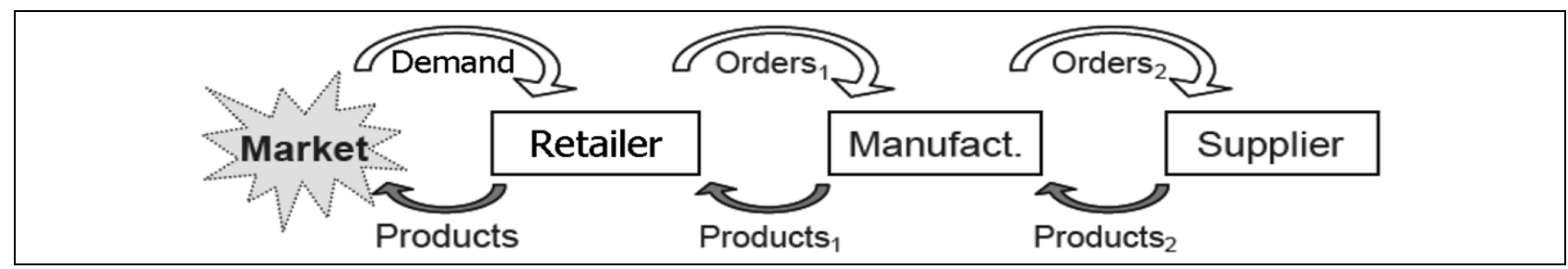

Fig. 4. Presentation of a three-stage supply chain

The simulation spreadsheets are designed in Microsoft Excel software (file size $270 \mathrm{~kb}$ ). For inventory policy, as one level constraint, we chose the min-max inventory policy but only for manufacturer stage in the supply chain. Manufacturer will place order to its supplier in predetermined review period. The order size is the difference between the required production level and the effective inventory level at the review time. Effective level is quantity of work in progress, net stock level plus backorder quantity:

Order $=$ required production level - work in progress - net stock level + backorder quantity

Inventory level is defined as:

$$
M I N \text { inv. level }=S S \cdot S f
$$

where:

$S S$ - safety stock,

$S f-$ safety factor. 
where:

MIN inv. level - minimum inventory level, MAX inv. level - maximum inventory level, $I N V l f$ - inventory level factor within limits $(1 \ldots 2)$.

Considering $S f$ the $S S$ is defined at limit where the minimum inventory level satisfies production rate and capacity utilization planed according to retailers demand. Usually the processes are planned at $85 \%$ of $O E E$ where production output totally complies with retailers demand and capacity utilization meets $100 \%$ (later in Fig. 5).

Considering the aforementioned for the second level constrain we chose the $O E E$ factor, which is considered in manufacturer and supplier lead time. Total lead time is the time taken by the demand and order to be processed to the retailer review period. It consists of manufacturer and supplier lead time.

$$
\begin{gathered}
L m=\frac{T m}{O E E m} \\
L s=\frac{T s}{O E E S} \\
L=L m+L s \\
P R=\frac{D}{L} \\
C U=\frac{P R}{\max P R} \times 100
\end{gathered}
$$

where:
$L m$ - manufacturer lead time,
Tm - manufacturer production lead time,
Ls - supplier lead time,
$T s$ - supplier production lead time,
$L$ - total lead time,
$P R$ - production rate,
$D$ - retailer's demand,
$C U$ - capacity utilization in \%.

In this paper, for bullwhip effect measure, the following equation is used:

$$
B E=\frac{V A R(\text { order })}{V A R(\text { Demand })}
$$

If the value of $B E$ is equal to one, then the order and demand variances are equal. Bullwhip effect is present in a supply chain if its value is larger than one. Where value of bullwhip is smaller than one it is assumed to have a smoothing scenario, meaning that the orders are less variable than the demand pattern.

Verification of the outputs of the model was done by tracing the values produced by the simulation and verifying them by hand using the mathematical equations from the model.

In real environment, because of various deviations in production process, the process is hardly $100 \%$ smooth. Therefore the $O E E$ level is taken into account. The 
$B E$ level equal to one is more theoretical because the difference between order variability and demand pattern is always present. We also assume that higher order variability and strength of the $B E$ can be reduced with proper inventory level policy. Some other assumptions in the model:

- The three-stage supply chain is working with a decentralized information sharing policy, where each stage calculates its demand forecast, based on the orders it gets from the downstream stage.

- Inventory control is based on continuous review ordering policy, where a new order is placed when the inventory level drops to the minimum inventory level.

- At manufacturer stage the inventory levelling policy is performed.

- Backorders are allowed, thus if one of the inventories cannot fulfil the whole order, it will keep the shortage amount as a backorder.

- Time series model: retailer performs autoregressive AR(1) model with $0<\varphi<1$ for the demand pattern and manufacturer performs exponential smoothing with $0<$ $\alpha<1$ for demand forecasting.

- The $O E E$ level is considered at manufacturer and supplier lead time to fulfil the orders.

- The review period is equal to total lead time.

- Week is the basic time unit in the model. One order per period (week) is presumed for each stage in the chain.

- The simulation starts with a stock amount equal to minimum required inventory level.

- If the inventory stock exceeds the target level, then the order equals zero. This means: no order is performed in that period.

\section{Simulation}

The aim of the simulation is to investigate the phenomenon of the bullwhip effect and identify the impact of different level constraints. The simulation model demonstrates the situation in 49 weeks. In the next three subsections the results of the supply chain model for different $O E E$ and inventory levels are presented.

\subsection{Case 1: Equal OEEm and OEEs (85 \%), and Inventory Policy with Defined SS and Planed Sf and INVlf}

Production processes are planed at $O E E$ of $85 \%$ and $C U$ of $100 \%$ where $P R$ meets the required amount of demand. Metter to this, there have to be chosen enough effective inventory policy with sufficient $S S$, efficient $S f$ and INVlf. Presence of deviation $(O E E$ level) in production process causes bigger order variability than demand pattern, which results in higher $B E$ than 1. Case 1 (Fig. 5) indicates stronger $B E$ in DSM. Because of constant demand and unsteady production process, stock fluctuates more easily, which means more frequent order variability. 


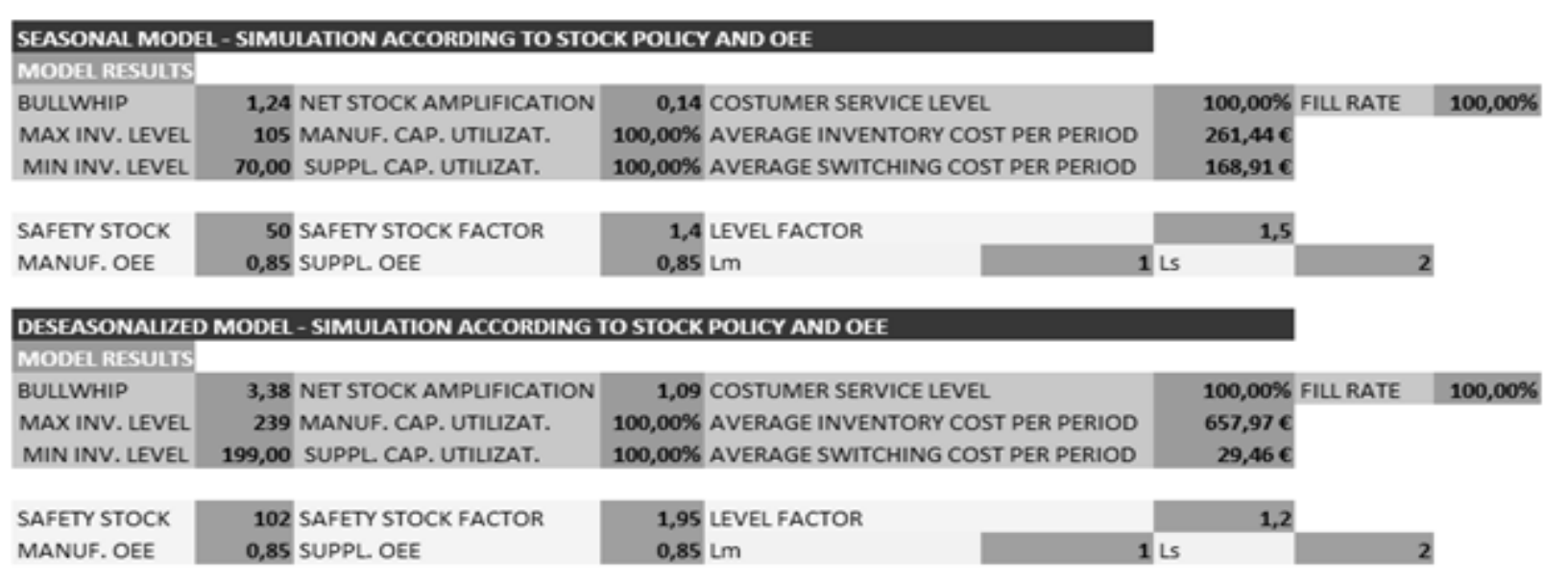

Fig. 5. Model results at OEEm and OEEs of $85 \%$

Because of the bullwhip phenomenon the difference between order and demand variances is higher. In order to reduce the $B E$ on reasonable level effective inventory policy have to be performed. DSM requires higher $S f$ and lower INVlf than SM. That means more limited inventory level at higher values. Because of more limited inventory the orders vary frequently at lower amplitude (Fig. 6). Simulation also indicates that cost effciency of supply chain in SM is higher (because of lover inventory level).

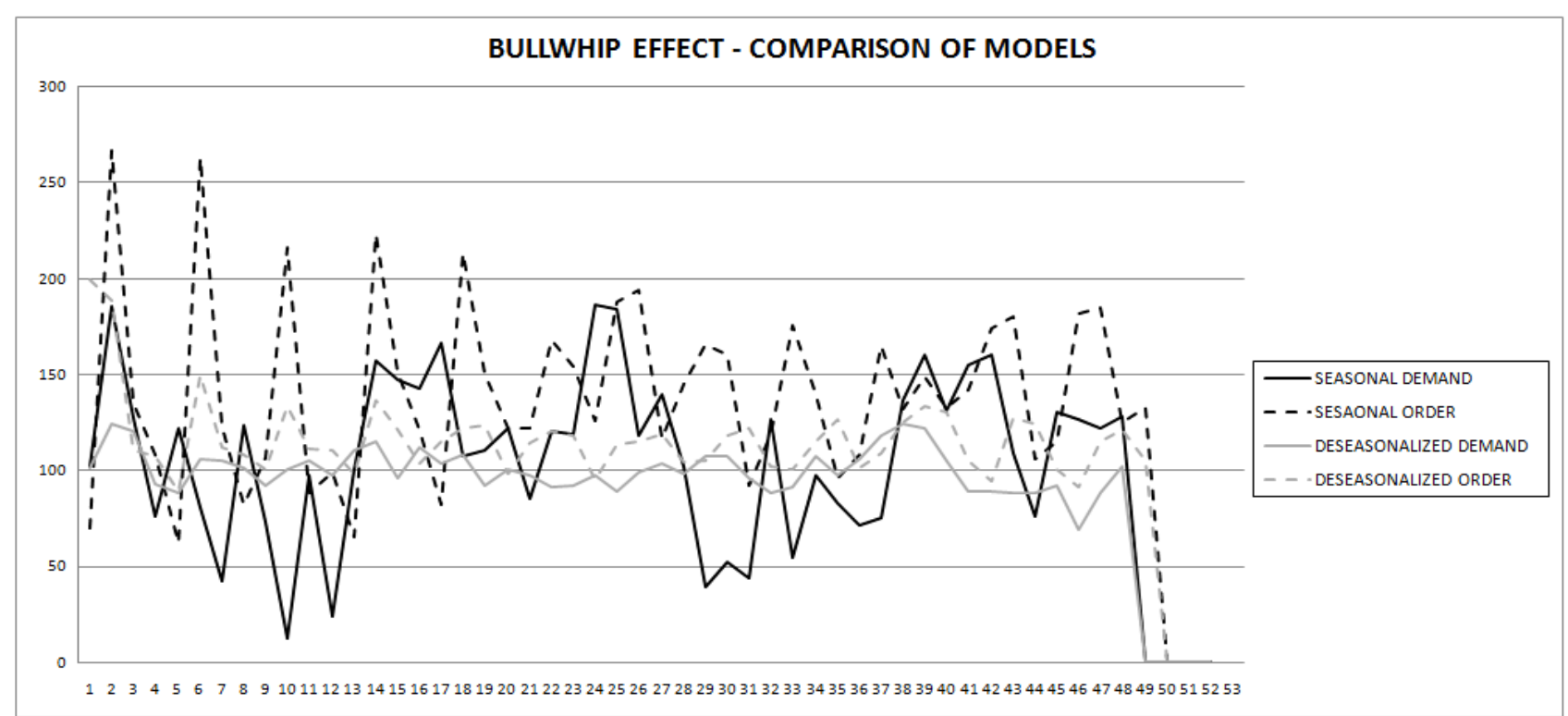

Fig. 6. Case 1 bullwhip effect comparison

\subsection{Case 2: Different OEEm and OEEs (85 \%, $75 \%)$ and Changed Inventory Policy with Defined SS and Variation of Sf and INVlf}

Different levels of $O E E$ at downstream stages in a supply chain daily occur in real environment. Downstream stage has higher deviations in production processes; that leads often to inefficient material supply. Incoming inventory level fluctuates more at upstream stage which leads to backorders and higher order variability. 


\begin{tabular}{|c|c|c|c|c|c|}
\hline \multicolumn{6}{|c|}{ SEASONAL MODEL - SIMULATION ACCORDING TO SIOCK POUCY AND OEE } \\
\hline \multicolumn{6}{|c|}{ MODEL RESULTS } \\
\hline BULLWHIP & 1,87 NET STOCK AMPUFICATION & 0,07 COSTUMER SERVICE LEVEL & $100,00 \%$ & FILL RATE & $100,00 \%$ \\
\hline MAXINV. LEVEL & 95 MANUF. CAP. UTILIZAT. & $100,00 \%$ AVERAGE INVENTORY COST PER PERIOD & $236,69 €$ & & \\
\hline MIN INV. LEVEL & 70,00 SUPPL. CAP. UTILIZAT. & $112,00 \%$ AVERAGE SWITCHING COST PER PERIOD & $289,02 \epsilon$ & & \\
\hline SAFETY STOCK & 50 SAFETY STOCK FACTOR & 1,4 LEVEL FACTOR & 1,35 & & \\
\hline MANUF. OEE & 0,85 SUPPL. OEE & $0,75 \mathrm{Lm}$ & & & \\
\hline \multicolumn{6}{|c|}{ DESEASONAUZZD MODEL - SIMULATION ACCORDING TO STOCK POUCY AND OEE } \\
\hline \multicolumn{6}{|c|}{ MODEL RESULTS } \\
\hline BULLWHIP & 3,57 NET STOCK AMPUFICATION & 0,83 COSTUMER SERVICE LEVEL & $100,00 \%$ & FILL RATE & $100,00 \%$ \\
\hline MAXINV. LEVEL & 229 MANUF. CAP. UTIUZAT. & $100,00 \%$ AVERAGE INVENTORY COST PER PERIOD & $633,81 \mathrm{\epsilon}$ & & \\
\hline MIN INV. LEVEL & 199,00 SUPPL. CAP. UTILIZAT. & $112,00 \%$ AVERAGE SWITCHING COST PER PERIOD & $26,96 €$ & & \\
\hline SAFETY STOCK & 102 SAFETY STOCK FACTOR & 1,95 LEVEL FACTOR & 1,15 & & \\
\hline MANUF. OEE & 0,85 SUPPL. OEE & $0,75 \mathrm{Lm}$ & & & \\
\hline
\end{tabular}

Fig. 7. Different $O E E m(85 \%)$ and $O E E s(75 \%)$, with variations of INVlf and $S f$

In case 2 (Fig. 7) simulation results indicate more frequent inventory fluctuation, due to downstream backlogs. Therefore in both models the net stock amplification and $B E$ was stronger than in case 1 . To reduce the strength of $B E$, reducing order variability has to be performed. For this matter the inventory level has to be optimized. In case 2 the INVlf in both models was decreased, which reduces the interval between min-max inventory levels.

Due to more unsteady stock fluctuation, changes are more frequent, which is more evident in DSM. With inventory optimization the amplitude of stock fluctuation was reduced. In DSM net stock fluctuates frequently with lower amplitude at higher level. Therefore the stock amplification is higher. Due to more limited inventory level the order variability is frequent at lower amplitude, leading to stronger $B E$ in DSM (Fig. 8).

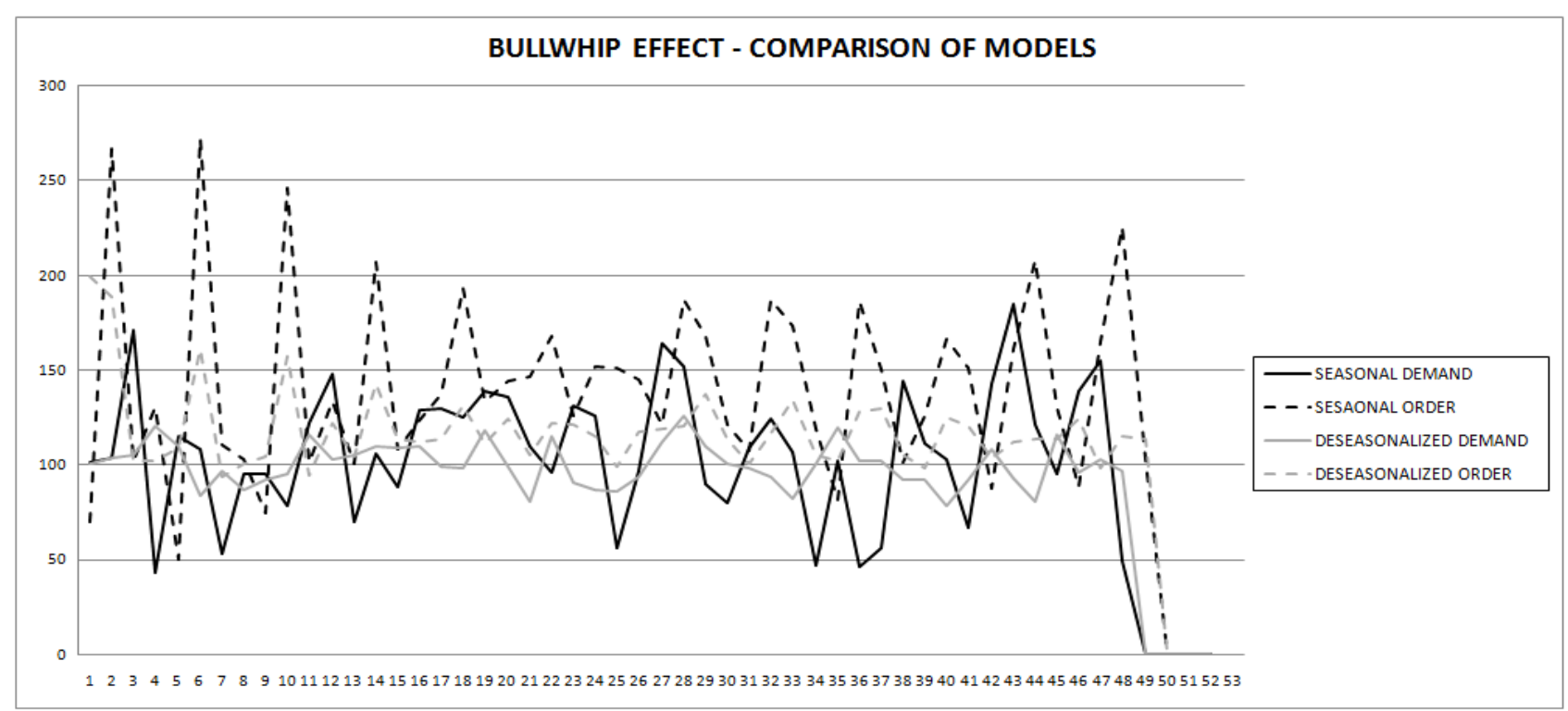

Fig. 8. Case 2 bullwhip effect comparison

Usually manufacturer cannot influence on supplier problems in production process. But he can stabilize the inventory with adapted inventory policy, with 
Buchmeister, B. \& Palcic, I.: Bullwhip Effect Simulation of a Supply Chain with L... changing and properly defining $S f$ and $I N V l f$ for optimum min-max inventory levels and for reducing $B E$.

\subsection{Case 3: Equal OEEm and OEEs (100 \%) and Changed Inventory Policy with Defined SS and Variation of Sf and INVlf of 1,5}

$O E E$ of $100 \%$ is more theoretical and can occur under ideal conditions. Despite prediction the deviation between demand and orders downstream in the supply chain occurs.

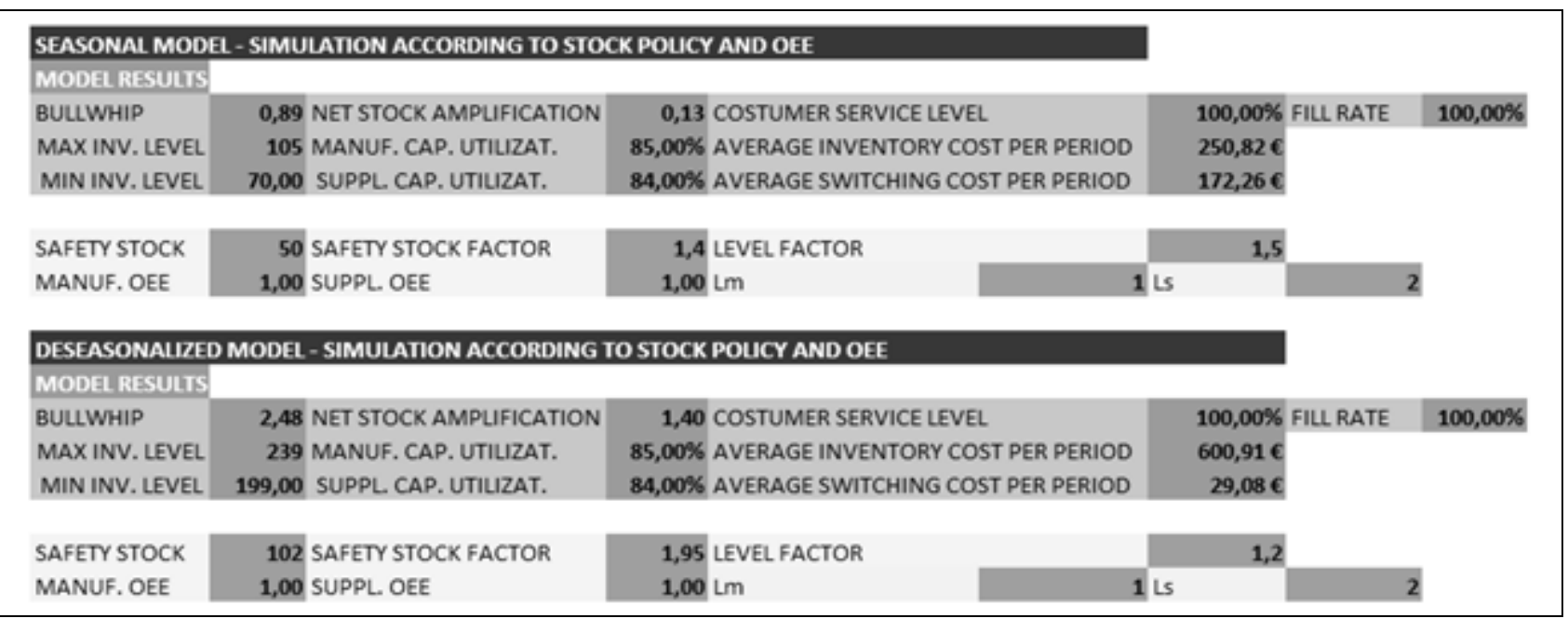

Fig. 9. Model results at OEEm and OEEs of $100 \%$

Simulation has shown the difference in variance between order and demand in DSM, because of order variability at constant demand pattern. Therefore the $B E$ even at $100 \%$ of $O E E$ is not equal to 1 . In SM we have a smoothing scenario (Fig. 10).

Simulation results indicate more cost effective SM at the same level of costumer delivery compliance because of required lower inventory level and smoothing scenario.

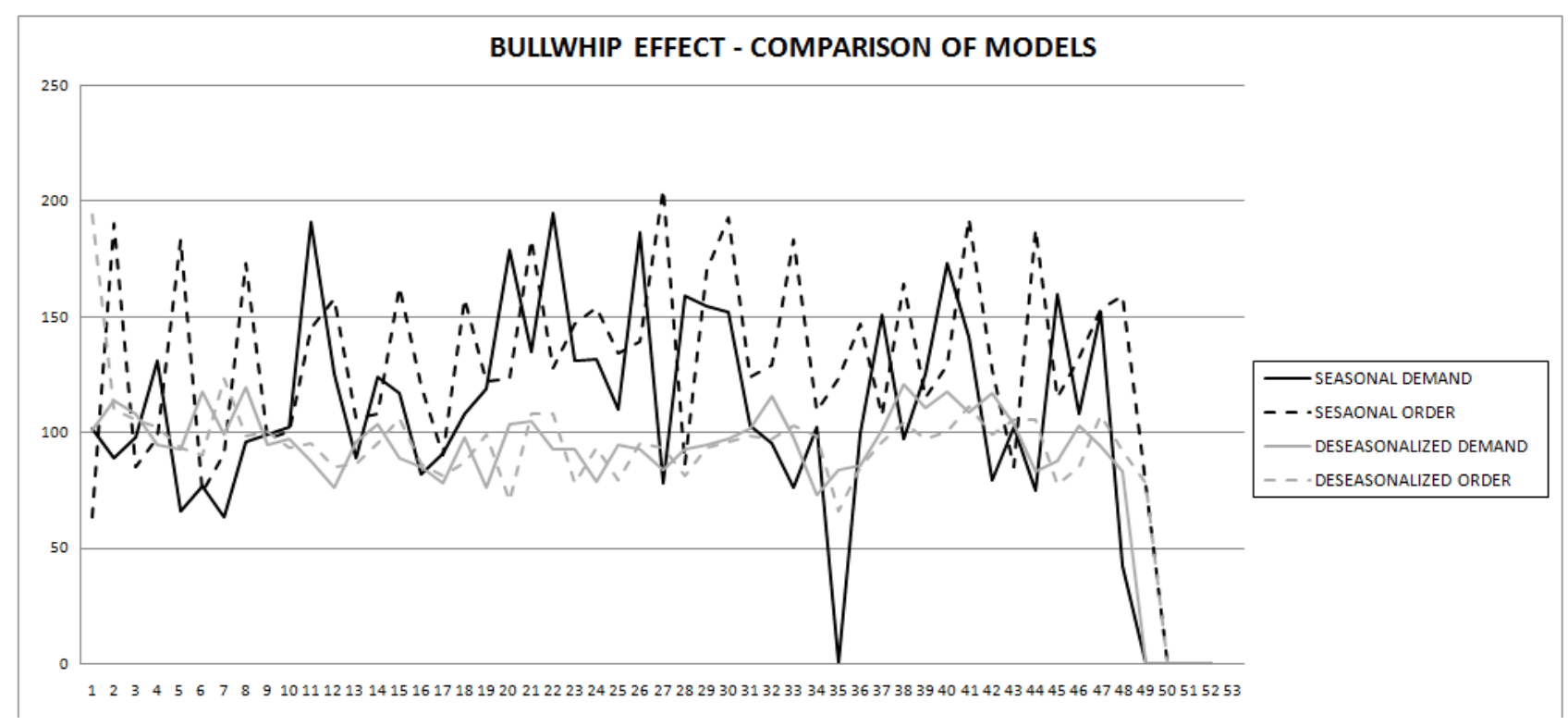

Fig. 10. Case 3 bullwhip effect comparison 


\subsection{Comparison of the Results for all Three Cases}

Simulation results (Table 2) indicate the weakest $B E$ in case 3, where ideal conditions (OEE of $100 \%)$ on all downstream stages in the supply chain were simulated. In SM there is smoothing scenario. In case 2 in DSM the $B E$ is strongest due to higher order variability at constant demand pattern. Case 2 is more likely in the real environment, where with proper inventory policy the $B E$ was reduced.

\begin{tabular}{|l|c|c|c|c|}
\hline \multicolumn{2}{|c|}{} & Case 1 & Case 2 & Case 3 \\
\hline & $B E_{S M}$ & 1,24 & 1,99 & 0,85 \\
& $B E_{D S M}$ & 3,38 & 3,45 & 2,12 \\
\hline Demand & $C O V_{S M}$ & 0,32 & 0,29 & 0,25 \\
Orders & $C O V_{S M}$ & 0,35 & 0,35 & 0,18 \\
\hline Demand & $C O V_{D S M}$ & 0,019 & 0,028 & 0,022 \\
Orders & $C O V_{D S M}$ & 0,108 & 0,078 & 0,069 \\
\hline
\end{tabular}

Tab. 2. Comparison of $B E$ and coefficient of variance $(C O V)$ for cases 1, 2, and 3

For $100 \%$ delivery compliance of a supply chain in SM, lower inventory level is needed. In all three cases coefficient of variance $(\mathrm{COV})$ is higher in SM due to less limited inventory policy and seasonal characteristic of time series. Because of higher order variability the order coefficient of variance in all three cases for both models is higher than demand coefficient of variance due to presence of $O E E$ levels downstream the supply chain.

\section{Discussion}

Our analysis is based on a developed MS Excel spreadsheet supply chain simulation model, working on the min-max inventory policy. Three cases of seasonal and deseasonalized models have been investigated, regarding the link between changing constraints parameters (overall equipment effectiveness and inventory policy with variable safety factor and inventory level factor) and bullwhip strength. In the existing literature we did not find any similar studies to compare the results.

We have find out that $O E E$ level on downstream stages has a significant influence on inventory fluctuation and order variability in the supply chain. Higher deviation in production process (lover $O E E$ factor) causes more frequent stock fluctuations. This brings frequent order variability and stronger $\mathrm{BE}$ at constrained inventory level policy. We have noticed that changing the inventory level with variations of INVfl and $S f$ has influence on BE strength.

The $P R$ and $C U$ are better when $O E E$ increases. At higher $O E E$ level manufacturers have less deviation in their production processes. Consequently orders to suppliers are more constant and more aligned with demand pattern. Therefore BE strength is lower. Because of constant demand pattern in DSM and non-steady manufacturer and supplier production rate, orders in DSM will vary more frequent than in SM. The difference between order and demand variance will be higher. Consequently at planed $O E E$ level the BE will be stronger in DSM than in SM. 
Considering $O E E$ level in DSM, higher $S S$ is needed. When material flow is steadier than expected, level of $O E E$ will be higher than $85 \%$, meaning lead time decreases and $C U$ will be under $100 \%$. When level of $O E E$ decreases below $85 \%$ then lead time increases and $C U$ will be more than $100 \%$ (e.g. more than 15 shifts per week). Stock consumption is more changeable at lower $O E E$ level.

\section{Conclusion}

Many manufacturers perform demand forecast in order to have steady material flow through production processes. They cannot predict various deviations in their processes which are calculated through different $O E E$ levels. Therefore they take into account $O E E$ level at their $P R$. This affects inventory planning and orders to suppliers which are usually higher than retailer demand. Results of simulation indicate that $O E E$ level and inventory level downstream the investigated supply chain have a significant impact on order variability and its frequency through the chain.

At higher $O E E$ level there is less deviation in production processes. Efficient inventory policy enables that orders to suppliers are more constant and more aligned with the retailer demand. In this case the bullwhip effect and net stock amplification will be lower.

At predicted demand increase of variability in production process causes decreasing $O E E$ level. Without adjustments in inventory policy, the bullwhip effect and stock amplification will increase. In terms of supply chain efficiency that mean inefficient deliveries. Considering $O E E$ level and constant demand pattern in the DSM, more frequent order variability is required. Bullwhip effect is stronger in DSM. Simulation results also indicate more cost effective SM than DSM at the same level of costumer delivery compliance, because of lower required inventory lavel.

Our future research will be focused to more complex suplly chains (networks) with multiple products, sharing the same suppliers, with more stages, incorporating other real restrictions and combinations of stock keeping policies.

\section{References}

*** http://web.mit.edu/jsterman/www/SDG/MFS/simplebeer.html, - MIT, Boston, Simple Beer Distribution Game Simulator (1963), accessed on 30-03-2013 Agrawal, S.; Sengupta, R. N. \& Shanker, K. (2009). Impact of information sharing and lead time on bullwhip effect and on-hand inventory. European Journal of Operational Research, Vol. 192, No. 2, 576-593, ISSN 0377-2217

Akkermans, H. \& Voss, C. (2010). The service bullwhip effect, $17^{\text {th }}$ International Annual EurOMA Conference, Porto, 10 pages

Alony, I. \& Munoz, A. (2007). The Bullwhip effect in complex supply chains, International Symposium on Communications and Information Technologies ISCIT 2007, 1355-1360

Ben Said, L.; Hmiden, M. \& Ghedira, K. (2010). A Two-Step Transshipment Model with Fuzzy Demands and Service Level Constraints. International Journal of Simulation Modelling, Vol. 9, No. 1, 40-52, ISSN 1726-4529 
Benyoucef, L. \& Xie, X. (2011). Supply chain design using simulation-based NSGAII approach, In: Multi-objective evolutionary optimisation for product design and manufacturing, Wang, L.; Ng, A. H. C. \& Deb, K. (Eds.), 455-491, Springer-Verlag, ISBN 978-0-85729-617-7, London

Bray, R. L. \& Mendelson, H. (2012). Information transmission and the bullwhip effect: An empirical investigation. Management Science, Vol. 58, No. 5, 860-875, ISSN 0025-1909

Buchmeister, B. (2008). Investigation of the bullwhip effect using spreadsheet simulation. International Journal of Simulation Modelling, Vol. 7, No. 1, 29-41, ISSN 1726-4529

Buchmeister, B.; Pavlinjek, J.; Palcic, I. \& Polajnar, A. (2008). Bullwhip effect problem in supply chains. Advances in Production Engineering \& Management, Vol. 3, No. 1, 45-55, ISSN 1854-6250

Cachon, G. P.; Randall, T. \& Schmidt, G. M. (2007). In search of the bullwhip effect. Manufacturing \& Service Operations Management, Vol. 9, No. 4, 457-479, ISSN $1523-4614$

Carvalho, H. \& Machado, V. C. (2009). Lean, agile, resilient and green supply chain: a review, Proceedings of the Third International Conference on Management Science and Engineering Management, Bangkok, Thailand, 59-69

Chen, L. \& Lee, H. L. (2012). Bullwhip effect measurement and its implications. Operations Research, Vol. 60, No. 4, 771-784, ISSN 0030-364X

Croson, R. \& Donohue, K. (2006). Behavioral causes of the bullwhip effect and the observed value of inventory information. Management Science, Vol. 52, No. 3, 323336, ISSN 0025-1909

Csik, A. \& Foldesi, P. (2012). A bullwhip type of instability induced by time varying target inventory in production chains. International Journal of Innovative Computing, Information and Control, Vol. 8, No. 8, 5885-5897, ISSN 1349-4198

Disney, S. (2009). Bullwhip Effect in Supply Chains. SciTopics, available from: $\mathrm{http} / / /$ www.scitopics.com/Bullwhip_Effect_in_Supply_Chains.html, accessed on 2011-12-13

Duc, T. T. H.; Luong, H. T. \& Kim, Y.-D. (2008). A measure of the bullwhip effect in supply chains with stochastic lead time. International Journal of Advanced Manufacturing Technology, Vol. 38, No. 11-12, 1201-1212, ISSN 0268-3768

Forrester, J. W. (1961). Industrial dynamics, MIT Press, Cambridge

Gilbert, S. M. \& Ballou, R. H. (1999). Supply chain benefits from advanced customer commitments. Journal of Operations Management, Vol. 18, No. 1, 61-73, ISSN 0272-6963

Glatzel, C.; Helmcke, S. \& Wine, J. (2009). Building a flexible supply chain for uncertain times. The McKinsey Quarterly, March Issue, 5 pages

Kelepouris, T.; Miliotis, P. \& Pramatari, K. (2008). The impact of replenishment parameters and information sharing on the bullwhip effect: A computational study. Computers \& Operations Research, Vol. 35, No. 11, 3657-3670, ISSN 0305-0548 Lee, L. H.; Padmanabhan, V. \& Whang, S. (1997). Information distortion in a supply chain: the Bullwhip Effect. Management Science, Vol. 43, No. 4, 546-558, ISSN 0025-1909 
Lyons, A. C.; Coronado Mondragon, A. E.; Piller, F. \& Poler, R. (2012). Supply chain performance measurement, In: Customer-driven supply chains, Lyons, A. C.; Coronado Mondragon, A. E. (Eds.), 133-148, Springer-Verlag, ISBN 978-1-84628875-3, London

Metters, R. (1997). Quantifying the Bullwhip Effect in supply chains. Journal of Operations Management, Vol. 15, No. 2, 89-100, ISSN 0272-6963

Nepal, B.; Murat, A. \& Chinnam, R. B. (2012). The bullwhip effect in capacitated supply chains with consideration for product life-cycle aspects. International Journal of Production Economics, Vol. 136, No. 2, 318-331, ISSN 0925-5273

Ouyang, Y. \& Daganzo, C. (2006). Characterization of the bullwhip effect in linear, time-invariant supply chains: Some formulae and tests. Management Science, Vol. 52, No. 10, 1544-1556, ISSN 0025-1909

Ouyang, Y. \& Daganzo, C. (2008). Robust tests for the bullwhip effect in supply chains with stochastic dynamics. European Journal of Operational Research, Vol. 185, No. 1, 340-353, ISSN 0377-2217

Ouyang, Y. \& Li, X. (2010). The bullwhip effect in supply chain networks. European Journal of Operational Research, Vol. 201, No. 3, 799-810, ISSN 0377-2217

Oyatoye, E. O. \& Fabson, T. V. O. (2011). Information distortion in supply chain: A simulation approach to quantifying the bullwhip effect. Journal of Emerging Trends in Economics and Management Sciences, Vol. 2, No. 2, 131-141, ISSN 2141-7024

Pishvaee, M. S.; Rabbani, M. \& Torabi, S. A. (2011). A robust optimization approach to closed-loop supply chain network design under uncertainty. Applied Mathematical Modelling, Vol. 35, No. 2, 637-649, ISSN 0307-904X

Pochampally, K. K.; Gupta, S. M. \& Govindan, K. (2009). Metrics for performance measurement of a reverse/closed-loop supply chain. International Journal of Business Performance and Supply Chain Modelling, Vol. 1, No. 1, 8-32, ISSN 17589401

Pujawan, I. N. (2008). Schedule instability in a supply chain: an experimental study. International Journal of Inventory Research, Vol. 1, No. 1, 53-66, ISSN 1746-6962 Shaikh, R. \& Khan, M. A. (2008). Quantifying bullwhip effect and reducing its impact, available from: $\mathrm{http}: / / \mathrm{ssrn} . \mathrm{com} / \mathrm{abstract}=1263741$, accessed on 2012-11-14 Simchi-Levi, D.; Kaminsky, P. \& Simchi-Levi, E. (2003). Designing and managing the supply chain, McGraw-Hill, ISBN 978-0072357561, New York

Sterman, J. D. (1989). Modeling managerial behaviour: misperceptions of feedback in a dynamic decision making experiment, Management Science, Vol. 35, No. 3, 321339, ISSN 0025-1909

Sucky, E. (2009). The bullwhip effect in supply chains - An overestimated problem? International Journal of Production Economics, Vol. 118, No. 1, 311-322, ISSN 0925-5273

Tominaga, H.; Nishi, T. \& Konishi, M. (2008). Effects of inventory control on bullwhip in supply chain planning for multiple companies, International Journal of Innovative Computing, Information and Control, Vol. 4, No. 3, 513-529, ISSN 13494198 